ORIGINAL ARTICLE

\title{
AVALIAÇÃO DO DESEMPENHO REPRODUTIVO EM SUÍNOS ENTRE AS TÉCNICAS DE INSEMINAÇÃO ARTIFICIAL PÓS-CERVICAL E INTRACERVICAL
}

\author{
Ana Maria Grigoletto ${ }^{1}$, Amanda Pífano Neto Quintal ${ }^{2}$, Andre Belico Vasconcelos $^{1 *}$
}

\section{RESUMO}

Com o objetivo de avaliar o desempenho reprodutivo de suínos, foram avaliadas duas técnicas de inseminação artificial. Foram utilizadas 60 fêmeas suínas, da linhagem DB 90 (DanBred), com média de idade de 22 meses e peso médio de $210 \mathrm{~kg}$. Conforme o delineamento experimental, as fêmeas foram subdividas em dois grupos, cada um contendo 30 animais, de forma aleatória. No primeiro grupo os animais foram inseminados com técnica de inseminação artificial pós-cervical, com 1,5 bilhões de espermatozoides em $50 \mathrm{ml}$, e no segundo grupo foi realizada a técnica de inseminação artificial intra-cervical, com 3 bilhões de espermatozoides em $80 \mathrm{ml}$. A análise estatística foi realizada por análise não paramétrica (Kruskal-Wallis) e teste das médias por Student-Newman-Keuls $(p<0.05)$. $\mathrm{O}$ número de retorno ao estro foi de $2 \mathrm{em}$ ambos os grupos (inseminação artificial póscervical $v s$ inseminação artificial intracervical), o número de abortos ( 0 vs 2), o número de partos (28 vs 26), a taxa de parição $(93,33 \%$ vs $86,68 \%)$ e o número de leitões nascidos totais $(14,07$ vs 14,10), respectivamente. A inseminação artificial póscervical, mostrou resultados semelhantes à técnica de inseminação artificial intra-cervical. Desta forma conclui-se que a técnica póscervical, possibilita uma série de vantagens ao produtor. Sendo possível, a redução do plantel de reprodutores.

Palavras-chave: Reprodução, linhagem DB 90, prenhez.

\section{INTRODUÇAO}

A carne suína é a fonte de proteína animal mais consumida no mundo, representando quase metade do consumo e da produção de carnes. O Brasil foi responsável, em 2013 por $3,13 \%$ da produção mundial, ou seja, 3.370 mil toneladas. É quarto maior produtor, atrás de China, União Europeia e Estados Unidos (ABIPECS, 2013). Em busca dos melhores resultados, a inseminação artificial torna-se uma ferramenta biotecnológica importante.

A inseminação artificial (IA) na suinocultura existe desde a década de 30 , porém foi desenvolvida e comercialmente aplicada na indústria, apenas na década de 80 (ROCA et al., 2006). Ela tem relevância na eficiência reprodutiva, sendo observado o número de leitões por porca por ano, tornando os parâmetros cada vez melhores graças às técnicas de inseminação artificial e outras biotecnologias que surgiram a partir dela (ALVARENGA, MURGAS e ZANGERONIMO, 2009). Em países da Europa como; Bélgica, Itália, Noruega, Dinamarca e Espanha, mais de $80 \%$ das fêmeas são inseminadas artificialmente, e na América do Norte (Estados Unidos, Canadá e México) e Brasil as porcentagens já chegam a $75 \%$ em granjas tecnificadas (ROCA, 2006). Desta forma, técnicas começaram a ser estudadas no final da década de 90, para a deposição do sêmen diretamente no corpo uterino, de forma cirúrgica e a não cirúrgica (ALVARENCA, MURGAS, e ZANGERONIMO, 2009).

A inseminação artificial intra-cervical é uma técnica fácil de ser executada, barata, pode ser feito com sêmen fresco ou resfriado, porém o número de espermatozoides utilizados é alto. Nesta técnica, a concentração de espermatozoides comumente utilizada é de 2,5 a 4 bilhões de células de espermatozoides por dose, sendo que o procedimento é feito duas a três vezes por estro (BORTOLLOZZO, GOLDENBERG e WENTZ, 2008), pois não há uma forma segura e rentável de predizer o exato momento da ovulação.

\footnotetext{
*Artigo recebido em: 03/07/2015

${ }^{1 .}$ Pós Graduação em Imunologia e Parasitologia Aplicadas - Universidade Federal de Uberlândia.

${ }^{2 .}$ Faculdade de Medicina Veterinária - Universidade de Uberaba
} 
*Corresponding author: devasconcelos.a.b@gmail.com ; andre.vasconcelos@uniube.br, Universidade de Uberaba Av. Tutunas 720, Uberaba- MG, Brazil, CEP: 38061-500, Fax: +55-34-33148910 Tel: 55-xx-34-33198942;

$\mathrm{Na}$ técnica de inseminação artificial pós-cervical, o sêmen é depositado diretamente no corpo do útero, desta forma há menores perdas, e requer menos células para se obter o mesmo desempenho reprodutivo. Porém, a técnica tem algumas limitações, uma vez que não é facilmente feita em marrãs, é mais cara, requer treinamento de quem executa a técnica, e pode lesionar a cérvix da fêmea se feita de forma errada. Entretanto os benefícios que podem ser alcançados são enormes, pois diminui o tempo da inseminação artificial, mais fêmeas podem ser inseminadas com espermatozoides de um macho de melhor qualidade genética, diminui o custo com mãode-obra, aumenta o desempenho reprodutivo e aumenta o rendimento de carcaça dos animais no abate, otimizado pelo uso de animais geneticamente superiores (MICKVICIUS, 2012).

O objetivo deste trabalho foi comparar as técnicas de inseminação artificial póscervical e intra-cervical, observando os parâmetros reprodutivos de número de nascidos totais por porca e taxa de prenhez, verificando a possibilidade de usar menor número de células espermáticas na primeira técnica, sem afetar na produtividade que é de extrema importância na produção de suínos.

\section{MATERIAL E MÉTODOS}

Local

O trabalho foi conduzido em uma unidade produtora de leitões (UPL), com um plantel em produção de 2000 matrizes, sendo uma granja comercial, no município de Patos de Minas, no período de 15 de Dezembro de 2014 a 20 de abril de 2015.

\section{Comitê de ética}

Protocolo do comitê de ética da Universidade de Uberaba em oficio CEEA077/2015 processo $\mathrm{n}^{\circ}$ 011/2015.

\section{Animais}

Foram utilizados 60 fêmeas suínas, da linhagem DB 90 (DanBred), com média de idade de 22 meses e peso médio de $210 \mathrm{~kg}$. Elas foram selecionadas de acordo com a ordem de parto que foi de 2 a 6 , animais sadios, sem problemas de aprumos ou corrimentos, e com score corporal entre 2 e 4 , sendo que, a escala é de 1 a 5 . Todos os animais foram alimentados no período de desmama até cobertura com $4 \mathrm{~kg}$ de ração ao dia, sendo divido em 4 porções, após a cobertura até 35 dias de prenhez foram dados $1,8 \mathrm{~kg}$ de ração apenas uma vez ao dia. Do $35^{\circ}$ dia ao $90^{\circ}$ eram dados $1,7 \mathrm{~kg}$ de ração uma vez ao dia, e dos 90 dias até o parto foram administrados $3,2 \mathrm{~kg}$ também apenas uma vez ao dia. Em todas as fases a oferta de água era à vontade.

As fêmeas foram subdividas em dois grupos, de 30 animais, de forma aleatória. $\mathrm{O}$ primeiro grupo foi aplicada a técnica de inseminação artificial pós-cervical e no segundo grupo a de inseminação intra-cervical.

Depois da desmama das fêmeas, foi realizada a detecção do estro, uma vez ao dia, pelo reflexo de tolerância ao homem na presença do macho. Neste momento o macho passa à frente das fêmeas, e o homem coloca a mão sobre o dorso de cada uma, se a mesma ficar parada, indica que este animal está no cio. As fêmeas que entravam em cio eram inseminadas no mesmo dia, e subsequentemente 24 horas depois, com no máximo 3 repetições. Conforme delineamento experimental.

\section{Procedimento experimental}

No primeiro grupo os animais foram inseminados com a técnica pós-cervical. Esta técnica consiste na introdução da pipeta através da vagina da porca, onde a mesma se fixa na porção inicial da cérvix, após, era colocado um cateter por dentro da pipeta, o qual deslizava até ultrapassar a cérvix, e então uma bisnaga contendo o sêmen diluído era colocada na parte posterior do cateter, e assim o mesmo era despejado diretamente no útero.

O sêmen utilizado foi recebido da central de produção de sêmen as terças e quintas e mantido conservado em temperatura adequada de $15^{\circ}$ a $18^{\circ}$ graus, sendo doses de 50 $\mathrm{ml}$, contendo 1,5 bilhões de células. Para confirmação da prenhez, o cio foi verificado novamente 18 a 22 dias após a cobertura, pelo reflexo de tolerância ao homem na presença do macho.

No segundo grupo as fêmeas foram inseminadas, pela técnica de inseminação artificial com o mesmo tipo de pipeta utilizadas na técnica anterior, porém sem o uso do cateter, desta forma a pipeta era introduzida 
através da vagina ficando presa na cérvix, então a bisnaga era fixada na pipeta, e o sêmen era depositado na cérvix, a dose do sêmen de mesma origem, era de 3 bilhões de células em $80 \mathrm{ml}$. Para confirmação da prenhez, foi feito o mesmo processo do grupo 1 , de forma que, o cio foi verificado novamente 18 a 22 dias após a cobertura, pelo reflexo de tolerância ao homem na presença do macho.

Em ambas as técnicas os animais foram inseminados em gaiolas individuais, e após a confirmação da prenhez, com média de 35 dias, os animais foram transferidos para baias em grupos de 20 animais, os quais os grupos foram divididos de acordo com a data de cobertura. Ficaram neste local até 4 dias antes da data de parição, e então foram encaminhadas para a maternidade.

\section{Estatística}

\begin{tabular}{ccc}
\multicolumn{2}{c}{ Os dados foram analisados usando o } \\
programa & SAS $\quad$ (Statistical Analyses
\end{tabular}
System). Para avaliar a taxa de concepção foi utilizada a análise não paramétrica (KruskalWallis) e o teste de Normalidade de Kolmogorov-Smimov correlacionando com Lilliefors. Teste das médias com StudentNewman-Keuls. A probabilidade de $\mathrm{P}<0,05$ foi considerada significativo.

\section{RESULTADOS E DISCUSSÃO}

No presente trabalho, foi observado que dos 30 animais utilizados no experimento por grupo, apenas 2 retornos ocorreram, totalizando $6,66 \%$ por técnica de todos animais utilizados no projeto (Tabela 1). Este resultado reforça o trabalho realizado por Dallanora et al. (2004), que descreveram baixas taxas de retorno em animais na linhagem Cambourough 22 (Agroceres-PIC). Assim a deposição póscervical de 1,5 bilhões de espermatozoides permitiu formação eficiente do reservatório espermático na junção útero-tubárica e adequada fecundação.

Tabela 1 - Comparação entre as técnicas de IA pós-cervical (G1) e intra-cervical (G2) de fêmeas suínas.

\begin{tabular}{|c|c|c|c|c|c|c|}
\hline Grupos & $\begin{array}{c}\text { Animais } \\
\text { cobertos }\end{array}$ & $\begin{array}{c}\text { Número de } \\
\text { retornos }\end{array}$ & $\begin{array}{c}\text { Número de } \\
\text { abortos }\end{array}$ & $\begin{array}{c}\text { Número de } \\
\text { partos }\end{array}$ & $\begin{array}{c}\text { Taxa de } \\
\text { parição (\%) }\end{array}$ & $\begin{array}{c}\text { Número de } \\
\text { nascidos }\end{array}$ \\
\hline $\mathbf{1}$ & 30 & 2 & 0 & 28 & 93,33 & $14,07^{\mathrm{a}}$ \\
\hline $\mathbf{2}$ & 30 & 2 & 2 & 26 & 86,68 & $14,10^{\mathrm{a}}$ \\
\hline
\end{tabular}

Letras na mesma coluna ( $\mathrm{p}>0.05)$. Grupo 1 IA pós-cervical; grupo 2 IA artificial intra-cervical.

Os dois abortos que ocorreram na técnica de inseminação intra-cervical, ocorreram após os 35 dias de gestação. Possivelmente, estes resultados foram decorrentes de processos traumáticos, ocorridos pela ocasião do agrupamento dos animais nas baias conjuntas, momento que, costumam ocorrer brigas entre os animais.

A taxa de parto no trabalho foi mais elevada do que comumente tem se observado na granja, de acordo com os dados coletados diariamente pela granja. Isso provavelmente ocorreu devido à seleção de animais com bom score corporal, sem problemas de aprumos e ordem de parto de dois a seis.

Relativo à taxa de parição, observou-se que não há diferença estatística entre as técnicas utilizadas $(93,33 \%$ vs $86,68 \%)$ técnica de inseminação artificial pós-cervical e técnica de inseminação artificial intra-cervical, respectivamente (Tabela 1). Estes resultados foram semelhantes aos encontrados por Sbardella (2013), que obteve média de 90,0\% com a inseminação artificial intra-cervical e 92,2 com inseminação pós-cervical. Porém devemos ressaltar, que o declínio da taxa de parição do grupo 2 deste trabalho, ocorreu devido ao agrupamento em baias e não pela utilização da técnica. Esta queda ocorreu ocasionalmente, pois ambos os grupos foram agrupados.

O número de nascidos vivos totais não é estatisticamente significativa, sendo 14,07 para a técnica de inseminação artificial póscervical e 14,10 para a técnica de inseminação artificial intra-cervical. Sendo que o resultado confirma o trabalho de Sena (2011), que relata em seu estudo, que as técnicas de inseminação artificial pós-cervical e intrauterina, não afetaram a prolificidade.

Desta forma a técnica que se obtêm, vantagens como a redução do volume das doses, redução do volume de espermatozoides por dose e mais doses por ejaculado, é a mais indicada. A técnica que melhor alcançou isso foi a de inseminação artificial pós-cervical. Para Marchetti, citado por Castagna et al. (2001), a técnica de inseminação artificial intra-cervical, o número de espermatozoides a ser utilizado, de doses inseminantes com 
menos de 3 bilhões de espermatozoides podem causar redução no tamanho de leitegada, enquanto que doses com menos de 2 bilhões de espermatozoides pode causar perdas na taxa de parto.

Na técnica de IA pós-cervical, há também diminuição do custo da mão-de-obra, por ser uma técnica mais rapidamente executada em pluríparas, pois o inseminador não precisa esperar a sucção feita pela fêmea, da dose inseminante, que ocorre na inseminação intra-cervical. Nessa técnica são gastos cerca de 7 a 15 minutos por fêmea, já na pós-cervical de 1 a 2 minutos, pois, o sêmen pode ser rapidamente depositado já que o mesmo é despejado diretamente no útero na técnica pós-cervical, numa criação de 600 matrizes, com 32 coberturas semanais, isso pouparia cerca 4 horas e 26 minutos (MICKEVICIUS, 2012).

\section{CONCLUSÃO}

Podemos concluir que a técnica póscervical, possibilita uma série de vantagens ao produtor. De forma que, os parâmetros reprodutivos analisados foram estatisticamente iguais, mesmo utilizando a metade do número de espermatozoides. Sendo assim, é possível a redução em do plantel de reprodutores, de forma que, é necessária uma menor infraestrutura para instalação desses animais, diminui custo com ração e também a taxa de reposição. Consequentemente há diminuição também do custo da dose inseminante, já que um macho passa a atender mais matrizes, pois as doses inseminantes são menores. Com diminuição do plantel, podem-se ter animais de genética superior e com melhores índices. Com essa superioridade dos machos doadores, obtêm-se retornos futuros nos animais produzidos. Desta forma, melhor conversão alimentar, melhor qualidade de carcaça e melhor taxa de crescimento.

AVALUATION OF
REPRODUCTIVE PERFORMANCE IN
SWINE BETWEEN THE TECHINIQUES
OF ARTIFICIAL INSEMINATIO POST-
CERVICA AND INTRACERVICAL

\section{ABSTRACT}

The aim of this study was to evaluate the reproductive performance in swine using two artificial insemination techniques. Were used 60 animals overall, the breed was DB 90 (DanBred) the average of the age was 22 months than weight $210 \mathrm{~kg}$. The experimental delimitation was divided into two groups, which one containing 30 animals, randomly. The first group the animal were inseminated with post-cervical artificial insemination technique, with 1.5 billons of spermatozoa in $50 \mathrm{ml}$, and in the second group was executed the intracervical artificial insemination technique, with 3 billons of spermatozoa in 80 $\mathrm{ml}$. The statistic was not parametric analyze (Kruskal-Wallis) and test of de averages by Student-Newman-Keuls ( $p<0.05)$. The number of return to estrus was 2 in both groups (postcervical artificial insemination $v s$ intracervical artificial insemination), the number of abortions ( $0 v s$ 2), the number of farrow (28vs $26)$, the farrowing rate $(93.33 \%$ vs $86.68 \%)$, and the litter size (14.07 vs 14.10), respectively. The post-cervical artificial insemination, showed similar results comparing with the intracervical artificial insemination. We conclude that the postcervical technique has several possible advantages for the producer, being possible the reduction of $40 \%$ to $45 \%$ of reproducers on the squad.

Keywords: Reproduction, DB 90 linkage, farrowing.

\section{AGRADECIMENTOS}

A Fundação de Amparo à Pesquisa do Estado de Minas Gerais (FAPEMIG) Programa de Mestrado em Sanidade e Produção Animal nos Trópicos da Universidade de Uberaba.

\section{REFERÊNCIAS}

ABIPECS. Estatística da produção mundial de carne suína. 2013. Disponível em: http://www.abipecs.org.br/pt/estatisticas/mundi al/consumo-2.html. Acesso em: 25 jul. 2015.

ALVARENGA, A. L. N.; MURGAS, L. D. S.; ZANGERONIMO, M. G. Tipos e volumes de diluentes para inseminação artificial intrauterina em suínos. Revista Brasileira de Zootecnia, v. 38, n. 10, p. 1886-1892, 2009. http://dx.doi.org/10.1590/S151635982009001000005

BORTOLLOZZO F. P.; GOLDBERG A. M. G.; WENTZ I. Até onde é possível reduzir o número de espermatozoides empregados na inseminação artificial intra-cervical em suínos 
sem comprometer a Fertilidade? Acta Scientiae Veterinariae, v. 36, n. 1, p. 17-26, 2008.

CASTAGNA, C. D.; BORTOLLOZZO, F. P.; WENTZ, I. Estratégias de inseminação artificial na suinocultura moderna. In: CONGRESSO DA ASSOCIAÇÃO BRASILEIRA DE VETERINÁRIOS ESPECIALISTAS EM SUÍNOS, 2001, Porto Alegre. Anais... Porto Alegre: ABRAVES, 2001.

DALLANORA, D.; MEZALIRA, A.; KATZER, L. H.; BERNARDI, M. L.; BORTOLOZZO, F. P; WENTZ, I. Desempenho reprodutivo de fêmeas suínas inseminadas pela técnica intra-uterina ou tradicional. Pesquisa Agropecuária Brasileira, v. 39, n. 8, p. 815-819, 2004. http://dx.doi.org/10.1590/S0100-

204X2004000800013

MICKVICIUS, E. Post cervical artificial insemination in sows - what, why, how? In: 12 th LONDON SWINE CONFERENCE - A TIME FOR CHENGE, 2012, London, Ontario. Anais... London: LSC, 2012.

ROCA, J.; VAZQUÉZ, J. M.; GIL, M. A.; CUELLO, C.; PARRILLA, I.; MARTÍNEZ, E. A. Challenges in artificial pig insemination. Reproduction in Domestic Animals, v. 2, p. 43-53, 2006. http://dx.doi.org/10.1111/j.14390531.2006.00768.x

SBARDELLA, P. E. Inseminação póscervical em primíparas suínas. 2013. $54 \mathrm{f}$. Dissertação (Mestrado Programa de PósGraduação em Ciências Veterinárias) Universidade Federal do Rio Grande do Sul, Porto Alegre, RS, 2013.

SENA, A. L. G. Condução da reprodução em suínos: análise zootécnica e estudo comparativo de técnicas de inseminação artificial. 2011. 59 f. Dissertação (Mestrado em engenharia zootécnica/Produção animal) Universidade Técnica de Lisboa, Lisboa, 2011. 